\title{
The Necessity of Flexibility with Regard To User's Satisfaction in Multifunctional Buildings of Traditional Architecture of Iran (Case Study: The Home-Hussainia of Aminiha)
}

\author{
Jamal-E-Din Mahdinejad \\ Assosiate Professor in Department of Architecture, Shahid Rajaee Teacher Training University, Tehran, Iran
}

\section{Seyede Fereshteh Ehsani Oskouei*}

Master of Architecture, Department of Architecture, Shahid Rajaee Teacher Training University, Tehran, Iran ${ }^{*}$ Corresponding Author

\section{Doi:10.5901/mjss.2016.v7n4s1p133}

\begin{abstract}
Nowadays importance and necessity of considering flexibility in designing spaces, especially in residential areas is more clarified. However this is not a newborn concept, in other words, it has been one of the main ideas followed by traditional architecture of many countries such as japan, china and Iran. In spite of the positive results and many benefits that evaluating manner of this concept in concern with technical weakness of those days, may lead to; Due to lack of enough and systematic observing, many aspects is still vague. In this paper, we will try to observe the idea of flexibility by a descriptive study on one of the famous traditional homes which is also used as a public gathering place for particular mourning ceremonies in special days of the year, so it needs to be adapted to changing and complex combining needs of the users by the aim of keeping them satisfied. at this point, first a framework for evaluating various characteristic of flexibility will be introduced and the study on this project will go on with regard to this system. This research indicates that some factors such as nested space, selective connectivity and disconnectivity, multiple entrances for each space and so many others can be useful for contemporary architecture of Iran .
\end{abstract}

Keywords: flexible architecture, multifunction spaces, satisfaction, the Home-Hussainia of Aminiha

\section{Introduction}

Considering flexibility notions in housing design can give users ability to take control of their environment based on their changing needs and wishes. When existing dwellings meet the user requirements, they will not become functionally obsolete because of their flexibility which provides user satisfaction [1].

Conversely Level of residential satisfaction gradually decreases by the time with the changing spatial needs of occupants. Users achieve satisfaction by changing the physical characteristics of their environments to create more adaptable and flexible spaces [2].

Studies has shown that the concept of flexibility is not a new topic, in spite of that, it has been considered as a basic principle in traditional architecture of many counties such as japan, turkey and Iran. Beside all the benefits flexibility can bring with itself, existence of that seems more critical by the times changing functions is required. For example in Iran, we have buildings with multi-functional characteristic like home-Hussainias which have both residential and religious aspects.it means they require adapting to various and complex functions in different days of the year.

In this essay, we will analyze solutions of these buildings toward meeting changing needs and demands in the special framework which has been derived from the theoretical background.

\section{Flexible Architecture}

\subsection{Definition of Flexibility}

There are various definitions of flexibility from different authors who have focused on this field of architecture, also there are some dissidence and discussion about differences of "flexibility" and "adaptability", but as we have considered the term "flexibility" as an inclusive concept that covers adaptability as well, it seems not necessary to mention details of this 
divergence. Here are some of the most influential definitions:

"Flexibility is the aptest term for designating at abstract level the property of dwellings and residential buildings which can be adapted in some way or other to the dynamic process of habitation" [3].

"Flexible architecture consists of buildings that are designed to respond easily to change throughout their lifetime". "Flexible buildings are intended to respond to the changing situations in their use, operation or location" [4].

"Our broad definition of flexible housing is housing that can adjust to changing needs and patterns, both social and technological. These changing needs may be personal (say an expanding family), practical (i.e. The onset of old age) or technological (i.e. The updating of old service). The changing patterns might by demographic (say the rise of the single person household), economic (i.e. The need to update housing to respond to climate change)". "It includes the potential to make changes prior to occupation as well as the ability to adjust one's housing over time after occupation" [5].

These descriptions inevitably reflect the authors' rhetorical preferences and their specific research focuses. However, a consensus on the essence of flexibility is clearly revealed, which can be defined as: the pre-arranged response to change. The change can be pre-occupancy (according to the users' personal preferences) or postoccupancy (as response to the inevitable obsolescence after many years); it can be generated by physical factors (such as the degeneration of the facade and pipelines), or non-physical causes (i.e. The shifts in lifestyle); it may be a common transformation which happens in a wide range (for example the increased size of living space which was found all over the state), or an individual activity (i.e. The re-division of interior space for a new family member); it may occur with comparatively low frequency (for example, the universal change of interior layout in China takes about ten years8 ), or with high frequency (i.e. The shift of specific uses within a year, a week, or even a single day); it probably has to be achieved by constructional approaches (some partitions need to be removed), or non-constructional method (i.e. By the simple re-organization of furniture) [6].

\subsection{Classifications of flexibility}

Beside various definitions, many authors categorize flexibility in different forms.to clarify the conceptual framework of the study better, some of the classifications will be investigated.

The first classification is for Dittert (1982) [7]. which is quoted in Hofland \& Lans (2005) [8], he classified flexibility into two groups: Functional flexibility and structural flexibility.

After that in 1990, Van Eldonk \& Fassbinder [9] added one group to the Ditteret"s categorization, which was "Character flexibility". So the outcome of this categorization became like below:

a) Spatial (structural) flexibility: This flexibility is not only related to structural changes but also to the physical alteration occurring in the interior space. Dwellers can change their houses according to their own preferences based on professional intervention.

b) Functional flexibility: the ability to change the condition without professional intervention. It is based on assigning new functions in redundant rooms, changing the room function or the relation between the rooms.

c) Character flexibility: possibility of changing the façade or dwelling identity aspects of architectural quality.

As an aim to more clarify this classification, many authors tried to determine some notions for each category, for example Al-Dakheel (2004) [10] and Gulaydin (2004) [11] quoted in Bakkaloğlu (2006) [12] added more detail to each category. By following them Hofland in 2005 set his own framework through various definitions and various kinds of flexibility. According to Hofland, there are different types of flexibility. These are:

1. Neutral for furnishing, (functional).

2. Possibility for change of floor plan, (structural).

3. Possibility to reshape apartments, (structural).

4. Modernization flexibility, (structural and functional).

5. Character flexibility (identity), (cultural).

6. Flexibility for changing safety requirements, (functional).

7. Wheel chair adaptability, (functional).

8. Capacity for expansion, (functional).

9. Multi functionality, (functional).

10. Finance flexibility, (functional).

11. Capacity to shrink, (functional).

12. Parking flexibility, (functional).

13. Robustness for calamities, (functional).

Many of these keywords were covered by former definitions and classifications. 
The following table which has been quoted in Gilani (2012) [1] shows different classifications of flexibility and the related notions of each category.

Table 1. Different classifications of flexibility including sub- definitions[1]

\begin{tabular}{|c|c|c|c|c|c|}
\hline \multirow{10}{*}{ 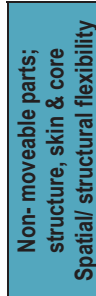 } & \multirow{6}{*}{$\begin{array}{l}\text { Extendibility } \\
\text { division }\end{array}$} & \multirow{6}{*}{$\begin{array}{l}\text { According to scale and } \\
\text { direction }\end{array}$} & \multirow[t]{2}{*}{ Component/ site scale } & \multirow[t]{3}{*}{ Horizontal } & Extension \\
\hline & & & & & Division \\
\hline & & & \multirow{4}{*}{ Building scale } & & Extension \\
\hline & & & & Horizontal & Division \\
\hline & & & & \multirow[t]{2}{*}{ Vertical } & Extension \\
\hline & & & & & Division \\
\hline & Form of roofs & \multicolumn{4}{|l|}{ Possibility of vertical extension } \\
\hline & \multirow[t]{2}{*}{ Structural method } & \multicolumn{4}{|c|}{ Incomplete/ indeterminate buildings; } \\
\hline & & \multicolumn{4}{|l|}{ Standardized modularization. } \\
\hline & Flexible Facade & \multicolumn{4}{|l|}{ Possibility of changing openings. } \\
\hline \multirow{4}{*}{ 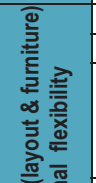 } & \multicolumn{5}{|c|}{ Versatility: spatial multi use with minor structural modification } \\
\hline & \multicolumn{5}{|c|}{ The ability to separate and rejoin the rooms and units in terms of movable partitions. } \\
\hline & \multirow{2}{*}{\multicolumn{2}{|c|}{ convertibility }} & \multicolumn{3}{|c|}{$\begin{array}{l}\text { Ability to convert space from one function to another without any structural } \\
\text { modification }\end{array}$} \\
\hline & & & \multicolumn{3}{|c|}{$\begin{array}{l}\text { Ability to exchange or interchange space functions without any structural } \\
\text { modifications }\end{array}$} \\
\hline$=\stackrel{0}{=}$ & \multicolumn{5}{|c|}{ Multi-functionality: the ability of having different functions at the same time, at the same place or by a same furniture. } \\
\hline 홍 & \multicolumn{5}{|c|}{ Flexible furniture: the ability to rearrange furniture } \\
\hline 혼 & \multicolumn{5}{|c|}{ The ability to place wet spaces within specific zones but not to be permanently, fixed, freedome of main space as generic space } \\
\hline & \multicolumn{5}{|c|}{ Adaptable to climate } \\
\hline & \multicolumn{5}{|c|}{ Adaptable to people with physical disabilities } \\
\hline$\frac{\pi}{\pi}$ & Individuality: change of & condition based on users perform & nances and their culture. & & \\
\hline 焉 & \multirow{2}{*}{\multicolumn{5}{|c|}{$\begin{array}{l}\text { cultural identify } \\
\text { Adaptable to different users with different identities }\end{array}$}} \\
\hline స్తై & & & & & \\
\hline 害范 & \multirow{2}{*}{\multicolumn{2}{|c|}{ Providing privacy }} & \multirow{2}{*}{\multicolumn{3}{|c|}{\begin{tabular}{|l} 
Exterior privacy: privacy for semi-private spaces (outer and inner hall) \\
Interior privacy: Privacy for private spaces
\end{tabular}}} \\
\hline & & & & & \\
\hline
\end{tabular}

\section{Home-Hussainia}

Hussainia is a congregation hall for Shia commemoration ceremonies, especially those associated with the Remembrance of Muharram.[1] The name comes from Husayn Ibn Ali, the grandson of Muhammad and the third Imam of the Shia Muslims. A Hussainiya is different from a mosque, because it is intended mainly for gatherings for Muharram in the mourning of Hussain ibn Ali, and may not necessarily hold juma'at, or Friday Prayer.

In these places various actions take place such as gathering, cooking, eulogy, mourning so the space should be flexible toward changing conditions and different functions.

\subsection{Case study: the Home-Hussainia of Aminiha}

Aminiha is one of the mature and beautiful samples of traditional homes by the manner of the Gajar style. This building was used as home-Hussainia from 1923 till 1963. In these years, residential function and mourning of the people simultaneity took place in this home.so in this paper we will discuss how this could be possible in concern with flexibility.

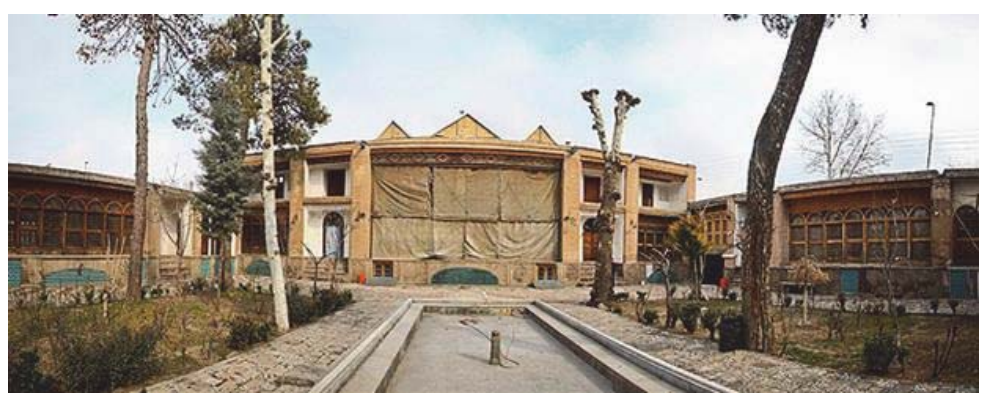

Figure 1. The the Home-Hussainia of Aminiha 


\section{Discussion and Analysis}

\subsection{Structural flexibility at the Home-Hussainia of Aminiha}

As it has been mentioned before, spatial/ structural flexibility is more concerned with professional interventions as a way to change the condition by the aim of satisfying dwellers, mainly depends on physical and structural features of the building.

In many traditional Iranian houses based on change in family size and situation and gradually increasing need for more private spaces, a separation in multi-functional yards and dividing bigger rooms into smaller living areas has been doable [13], also if enough land was available and it may not disturb form, or construction of the dwellings as well as unity and harmony in the facades, Horizontal extension could be observed due to modularity. In this case, due to existence of four yards, enough entrances to the complex and regular configuration, technically it is possible to divide it into smaller independent sets, but in regard to religious issue of dedication ,this kind of change may has been restricted.

In building scale we should consider structural system of the hosseyneye Aminiha, as like as any other common buildings of that period, load bearing walls which has brick vault and dome system in the basement and sloped roof at the top level, therefore vertical extension in this scale (possibility to add one story) is restricted and division is not desired though.

In spite of impossibility to rearrange the position of walls for making changes, due to the building technology of traditional Iranian architecture, They can respond to various conditions by changing the relation of spaces [14] just like as home-hosseyneye of Aminiha that has achieved this goal by dynamic partitions between three main spaces of semipublic zone or guest rooms. In other words space A has been divided into three sub-spaces with two large decorated windows named "Orsi" .by sliding windows up and down, connection quality and area quantities of these rooms could be controlled. It means we could have three separate spaces, or two separate spaces or one large space and this is completely relates to applying flexibility rules. In conjunction with that due to the relevant spaces, large number of access doors to each room, hanged curtains, opened windows, and Orsis, all spaces have potential to be combined or separated [15].

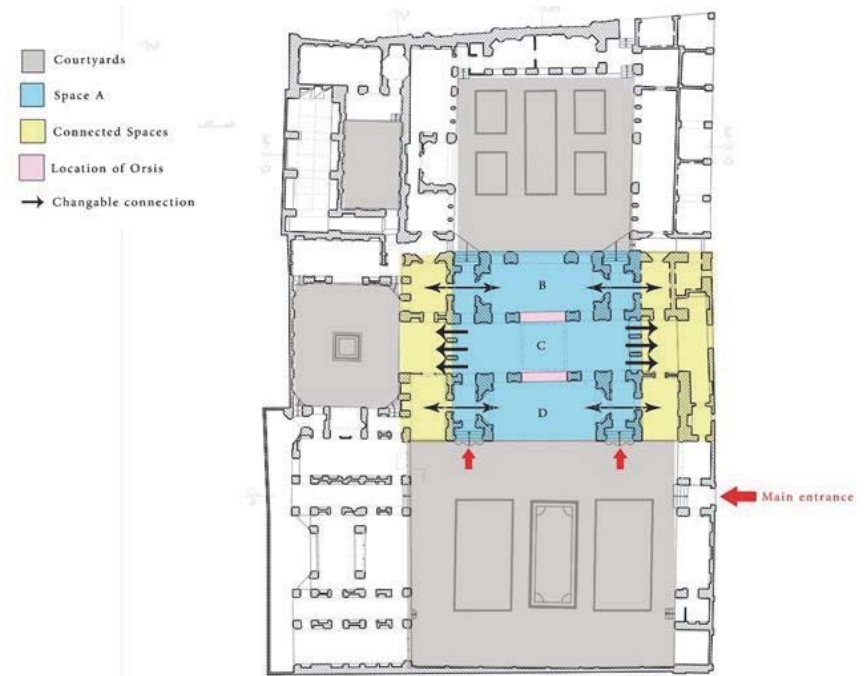

Figure 2. Spatial configuration of the the Home-Hussainia of Aminiha

Today, the method of structure known as "polyvalent organizations", is one of the main structural methods for achieving flexibility. This method was based on the permanent modules with standardized dimensions which were appropriate for different functions. It was introduced by Hertzbeger in 1991 as a flexible structure [1]. In traditional homes of Iran, this idea was implemented by a specific module named "Peymun", proportion and dimensions of full and empty parts were signified with this Peymun too. following the main geometry and pattern made flexibility and convertibility during various conditions and passing eras possible. This modularity and plan organizations of the houses were reflected to the facades directly too [16]. 
Table 2. Summary of notions of structural/spatial flexibility in home- Hussainia of Aminiha

\begin{tabular}{|c|c|c|c|c|c|c|}
\hline \multirow{10}{*}{ 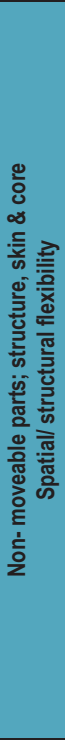 } & \multirow{6}{*}{ 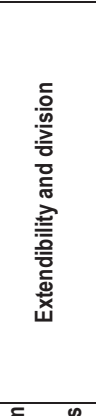 } & \multirow{6}{*}{$\begin{array}{l}\text { According to scale and } \\
\text { direction }\end{array}$} & \multirow[b]{2}{*}{$\begin{array}{l}\text { Component/ } \\
\text { site scale }\end{array}$} & \multirow[b]{2}{*}{ Horizontal } & Extension & $\begin{array}{l}\text { It could be possible if the land was available and no } \\
\text { disturbance of the form, construction or unity and harmony in } \\
\text { the facades due to modularity }\end{array}$ \\
\hline & & & & & Division & $\begin{array}{l}\text { Though technically It could be possible due to modularity, } \\
\text { existence of } 4 \text { courtyards and enough entrances and regular } \\
\text { configuration but some religious issues prevent that. }\end{array}$ \\
\hline & & & & Horizontal & Extension & $\begin{array}{l}\text { Combining rooms into a large one has been considered, } \\
\text { although bearing wall system is restrictive somehow. }\end{array}$ \\
\hline & & & & & Division & $\begin{array}{l}\text { Taking as a whole, although it's not perfectly free, Sliding } \\
\text { "orsis" makes it partly passible. }\end{array}$ \\
\hline & & & Building scale & & Extension & It is limited due to load bearing walls and inclined roof. \\
\hline & & & & Vertical & Division & $\begin{array}{l}\text { Won't have desirable results due to its design idea and } \\
\text { ornaments. }\end{array}$ \\
\hline & 톤 ‘ & None-flexible & clined ronf $m$ & kes adding & one another & story limited. \\
\hline & 물 & $\begin{array}{l}\text { Incomplete/ indeterminate } \\
\text { buildings; }\end{array}$ & & & & \\
\hline & 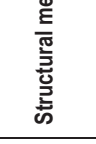 & \begin{tabular}{lr} 
Polyvalent & \multicolumn{2}{c}{ organization: } \\
permanent & "modules" with \\
standard & dimensions \\
appropriate for diverse \\
functions
\end{tabular} & $\begin{array}{l}\text { Various type } 0 \\
\text { room, Shahne } \\
\text { were suitable f }\end{array}$ & $\begin{array}{l}\text { house orga } \\
\text { hin and so } \\
\text { r diverse fur }\end{array}$ & $\begin{array}{l}\text { nization due } \\
\text { on) which ar } \\
\text { ictions. }\end{array}$ & $\begin{array}{l}\text { to combination of defined rooms (three-door room, five-door } \\
\text { e based on Peymun modularity. Dimension of the modules }\end{array}$ \\
\hline & 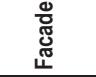 & Flexible & Modularity ba & d on "Peyn & un" and plar & n organization reflected to the facades during design. \\
\hline
\end{tabular}

\subsection{Functional flexibility at the Home-Hussainia of Aminiha}

The ability to change the condition without professional intervention is the main point in evaluating this factor. Assigning new functions or changing the former functions or rearranging the relation between spaces are three manners to achieve this so-called functional flexibility.

As it has been discussed before, because of load bearing wall system and lack of today's technology, structural modification in the rooms for spatial multi-use has been limited. Nevertheless, It is possible to observe the large space which is divided into a number of sub-spaces by using some tools such as the "osrsi".that is to say each of these subspaces could have various functions and they could exchange and convert their functions with each other as well. In other words, the spatial arrangement in this home like the other traditional architecture of Iran is totally flexible toward requirements and living ways. There is no obstructed space in these houses. Each space, besides its dependent function, has the potential to combine with other spaces. Two free spaces such as three-door rooms and back rooms could create a bigger room for gatherings and ceremonies and the court yard, have the ability to get combined and create a bigger area and show the maximum capacity of the house [15].

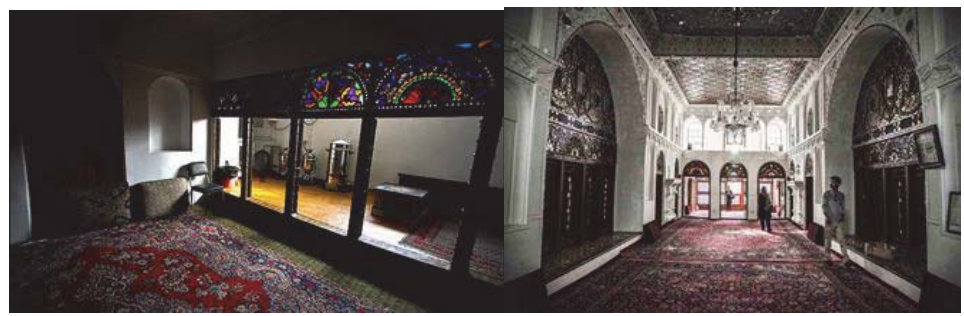

Figure 3 and 4. Extension of interior spaces

What is more, capability of neutral access to the rooms through yard and connecting aisles helps functional diversity. This way of internal connections lead to a combination of internal spaces and reduce the wasting of space for connecting corridors [16].Furthermore, as we can see there is some kind of coherence among spaces of our case study which is controllable by some facilitates and is a manner of accomplishment to flexibility.

The other noticeable potential that shouldn't be ignored is the role of multi-functional concept in the design of the 
spaces. It's being so, Variability in dimensions, situation and shape but in concern with special modularity "Peymun" provides the ability to use the spaces in different ways in depend on the spatiotemporal characteristics of the operations and functionality of the building. By definition, any space can be used in different ways for several purposes in predefined period of time or even for different functions in a certain time as well [13].

As prove for not functional allocation of the rooms, the name of spaces in traditional houses, unlike modern ones is a kind of representative of their functions. This means that in Iranian traditional houses, rarely there were spaces called as bedroom, living or dining rooms, most of them were named as concepts such as three-door, five-door and alcove room [17] For example, a room could be operated as the living room during the day time and be used as a bedroom during the nights. Some of these relations between space and function which depends on time of the use is reflected in table 3.

Table 3. Relations between function and the space

\begin{tabular}{|c|c|c|c|c|c|c|c|c|}
\hline & $\begin{array}{l}\text { 을 } \\
\text { ํㅗㄴ }\end{array}$ & 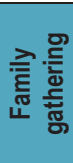 & ס & $\begin{array}{l}\text { 일 } \\
\frac{\text { 응 }}{8}\end{array}$ & $\begin{array}{l}\frac{0}{\mathrm{E}} \\
\frac{\mathrm{O}}{\mathrm{O}} \\
\frac{\mathrm{o}}{\infty}\end{array}$ & 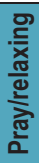 & 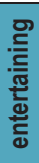 & 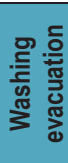 \\
\hline \multirow{2}{*}{ 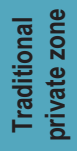 } & rooms & * & * & & * & * & * & \\
\hline & kitchen & & & * & & & & * \\
\hline \multirow{3}{*}{ 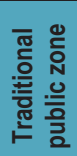 } & Court yard & * & * & * & * & * & * & * \\
\hline & $\begin{array}{c}\text { Talar } \\
\text { (guest room) }\end{array}$ & & * & & * & & & \\
\hline & hall & * & * & & * & & & \\
\hline
\end{tabular}

In conjunction with that, in a smaller scale, elements such as windows and doors unlike their present specific functions also have been used as multi-function elements serving to connect the yard, room sand gates, lightening the internal corridors and spaces and similar functions at the same time [16].In addition we can acclaim that, in this case nearly every used furniture has more than one purpose of use. As an example, the niche named "Rafe" which is depicted in pic 5 is not only a sound-booster for improvement of the encomiast's voice quality, but also if a candle is placed on them, due to the mirror decoration of the Rafe, total amount of the light will be strengthened.

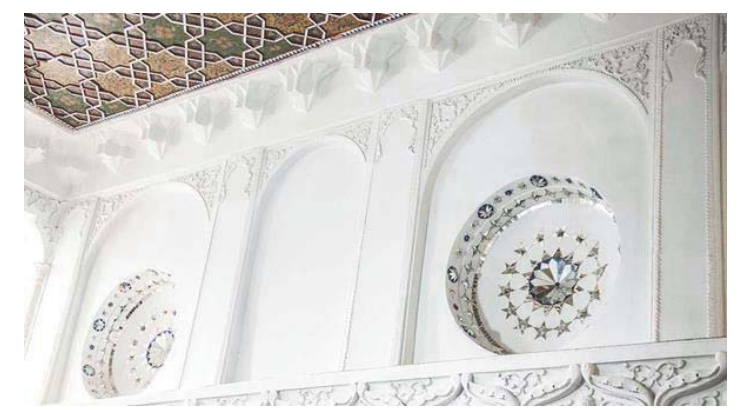

Figure 5. Rafe which is multi-functional niche in this case

Along side with that, most of the furnishings used here, are not fixed and can be easily moved. For example we don't have somethings like chair, table or bed which take a lot of space and is not all the time useable but some kind of lightweight throw pillows showed in pic 6 are common by aim of assembling comfort for users. The advantage of these accommodations is that they can be moved in concern with the changing demands, in addition, they are not bulky therefore more people could be seated in the room. In conjunction with that, because the interior was left free from any constructional elements, so furniture could be rearranged anytime needed. 


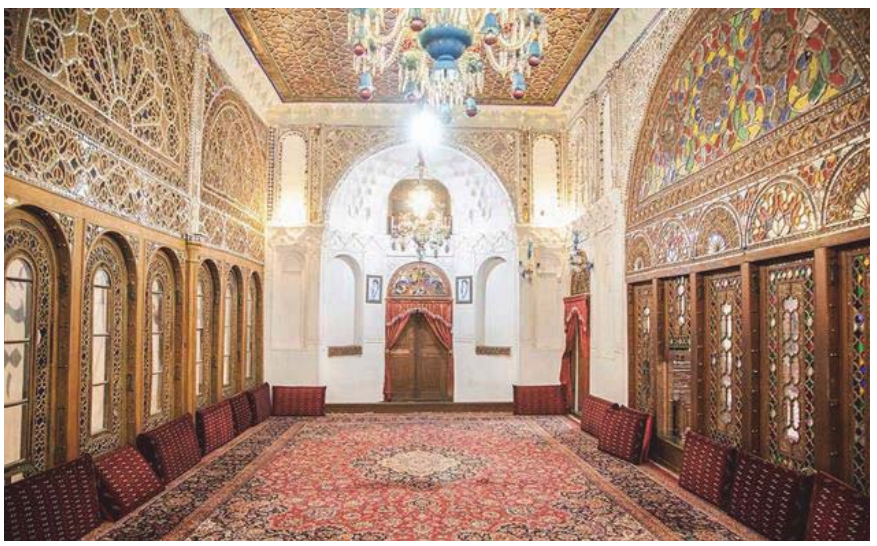

Figure 6. Moveable lightweight throw pillows

Another method utilized here to attain flexibility, is separating service areas from others. Generally speaking, In traditional houses, wet spaces were located in a specific zone and the rest were left as a generic space. Here in the Aminiha house, wc is located in the courtyard, consequently changing the layout of the house is more easy.

Next aspect of the functional flexibility is connected with the climate, in other words, how space can react or adapt to changing climate as an aim to temporal tranquility of the users. It comes more vital, while the population amount is not constant. By studying this issue at the Aminiha project we should consider two main functions of the building as well, in other words both residential and social or gathering place for specific mourning ceremonies. As a home, like the other traditional houses of Iran, many aspects have been considered to accommodate more with outdoor conditions such as Separating of living spaces for summer and winter times in accordance with the change in needs of residents and as a social space, heat stress caused by the crowd can make people inside annoyed or lead to decrease in arousal threshold [18]. So with sliding the Orsi upward and combining three sub-spaces to one, the percept of the space capacity changes and thus the sense of aggression to their privacy decreases .

Table 3. Summary of notions of functional flexibility in home- Hussainia of Aminiha

\begin{tabular}{|c|c|c|c|}
\hline \multirow{8}{*}{ 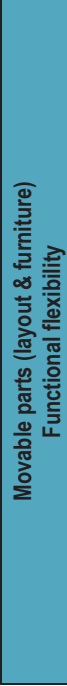 } & \multicolumn{2}{|c|}{$\begin{array}{l}\text { Versatility: spatial multi use with minor structural modification } \\
\text { The ability to separate and rejoin the rooms and units in terms } \\
\text { of movable partitions. }\end{array}$} & $\begin{array}{l}\text { it is limited due to load bearing wall system, inclined roof and lack of technology. } \\
\text { Possibility of joining two rooms with each other and then separate them sliding the } \\
\text { Orsi up and down. Although it's not as complete as moving partitions in modern } \\
\text { architecture. }\end{array}$ \\
\hline & convertibility & $\begin{array}{l}\text { Ability to convert space from one function to } \\
\text { another without any structural modification }\end{array}$ & $\begin{array}{l}\text { It is possible due to non-labeled space as well as the dimension of rooms was } \\
\text { suitable for any function. in this case ,Neutral access from the courtyard to the } \\
\text { rooms is helpful too. }\end{array}$ \\
\hline & & $\begin{array}{l}\text { Ability to exchange or interchange space } \\
\text { functions without any structural modifications }\end{array}$ & $\begin{array}{l}\text { Possibility of exchanging room's function due to non-labeled space and dimension } \\
\text { of rooms was suitable for any function. } \\
\text { Also Variability in dimensions, situation and shape provides the ability to use the } \\
\text { spaces in different ways in depend on the spatiotemporal characteristics of the } \\
\text { operations and functionality of the building. }\end{array}$ \\
\hline & \multicolumn{2}{|c|}{$\begin{array}{l}\text { Multi-functionality: the ability of having different functions at } \\
\text { the same time, at the same place or by a same furniture }\end{array}$} & $\begin{array}{l}\text { It is possible due to appropriate dimension of rooms and non-labeled spaces. } \\
\text { Mainly all furniture and elements have more than one function. }\end{array}$ \\
\hline & \multicolumn{2}{|c|}{ Flexible furniture: the ability to rearrange furniture } & $\begin{array}{l}\text { It is possible due to non-labeled spaces and mostly non-fixed furniture. } \\
\text { Dimensions of the rooms were suitable for rearranging of the furniture. } \\
\text { Leaving the interior free from any constructional elements. } \\
\end{array}$ \\
\hline & \multicolumn{2}{|c|}{$\begin{array}{l}\text { The ability to place wet spaces within specific zones but not to } \\
\text { be permanently, fixed, freedome of main space as generic } \\
\text { space }\end{array}$} & $\begin{array}{l}\text { Locating wc in the courtyard and leaving the rest as a generic space. Possibility of } \\
\text { rebuilding it in another location in the same courtyard. }\end{array}$ \\
\hline & \multicolumn{2}{|c|}{ Adaptable to climate } & $\begin{array}{l}\text { Like other traditional houses of Iran, many features have been considered like as } \\
\text { Separating of living spaces for summer and winter times in accordance with the } \\
\text { change in needs of residents }\end{array}$ \\
\hline & \multicolumn{2}{|c|}{ Adaptable to people with physical disabilities } & It was not seen, however, there is not too much level difference in the dwelling. \\
\hline
\end{tabular}




\subsection{Cultural flexibility at the Home-Hussainia of Aminiha}

Among the three aspects of flexibility explained before, cultural flexibility seems to play the most critical role here. first and foremost it is a home and In fact, the home is a position that directly reflects the personality and status of the occupants, so architects are expected to design the houses in such a way that is adaptable to various users with different cultures, beliefs, life styles and needs. The users should have the ability to change their conditions based on their needs, tastes and cultures[1].in conjunction with that, it is also used as a public place in some special days of the year, so quality of connection among the physical spaces with its new undefined users is really important. In home-Hussainias the number of users is as uncertain as the proportion of the women in compare to the men, consequently as it's shown in the pic, by sliding the windows of Talars (guest rooms) toward up and down, changing in areas and zone boundaries with regard to privacy which is needed, are doable. Also while the crowd indoor is excess, with opening windows of the façade, fully connection of indoor and outdoor space makes it possible to stretch the ceremony to the courtyard.

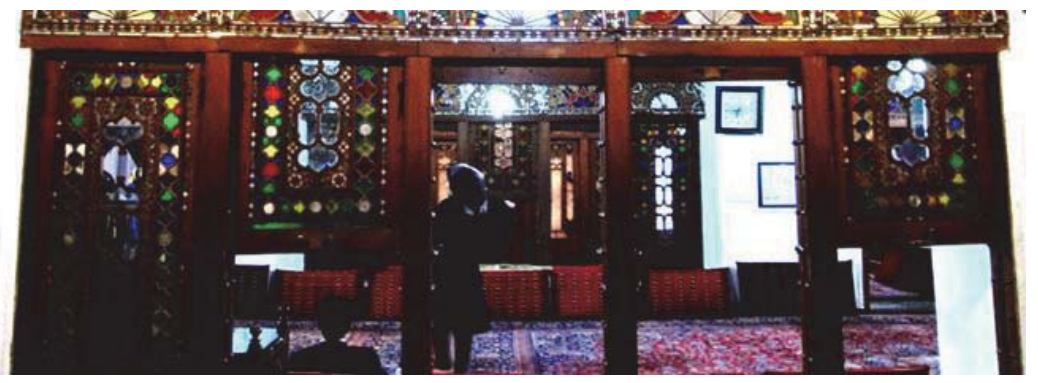

Figure 8. Sliding Orsis

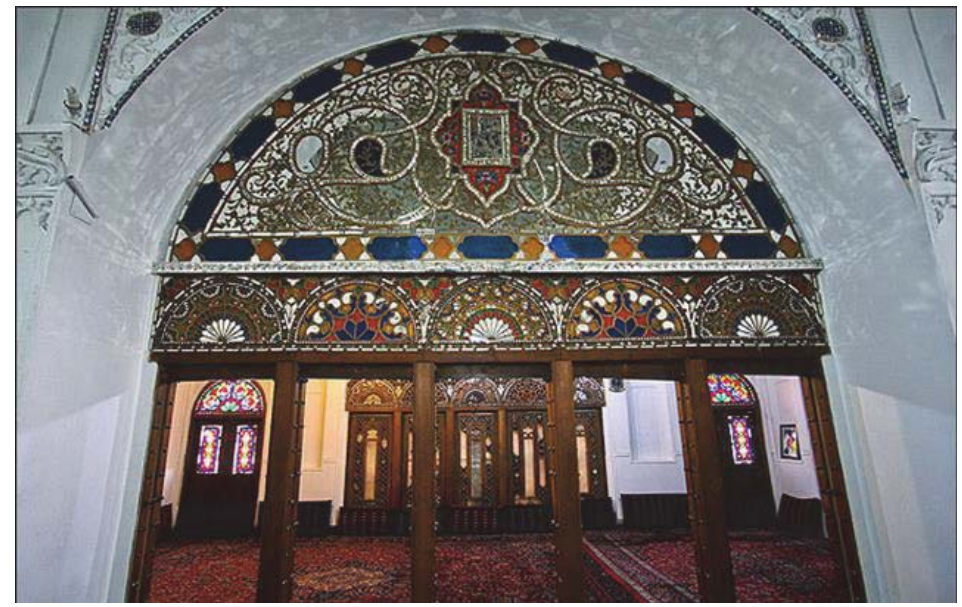

Figure 9. Combining of 2 spaces by sliding Orsis upward

According to the culture of residents of Islamic Iran, privacy is an important requirement for them, chiefly in their living areas, therefore The concepts of privacy and hospitality have had a great impact on their house formation[6] Iranian family both needs to have privacy as well as social contact with neighbors'. In order to achieve this aim, the hierarchy of spaces starts with a public space and it continues with a semi-public space, semi- private and at last a private space. Spatial configuration divides the whole house into spaces with different characteristics such as the entrance, the exterior (guest room) and the interior (private rooms) [19]. 
Table 4. Summary of notions of cultural flexibility in home- Hussainia of Aminiha

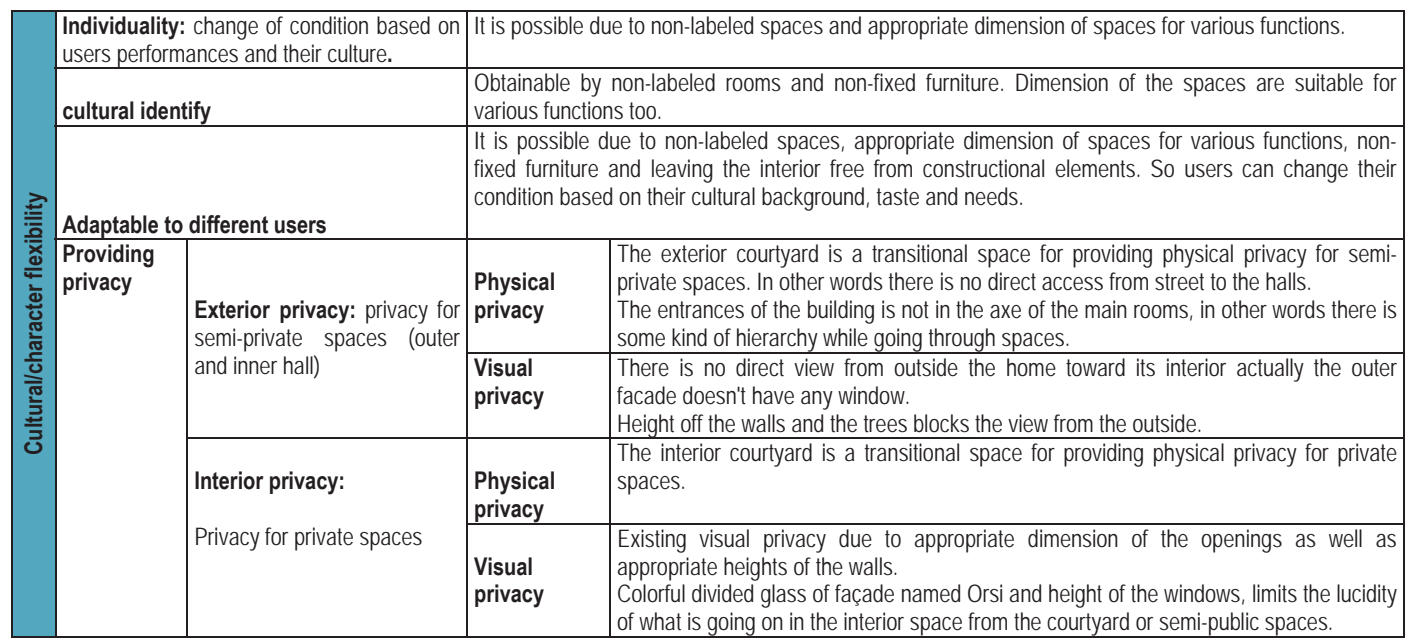

\section{Conclusion and recommendation}

it can be concluded that the home-hosseineir of Aminiha in spite of some technical weakness leaded to limited structural flexibility, is still able to come up with changing condition and new demands of it's undefined users. In this project, functional and cultural flexibility is provided due to modularity, appropriate space dimensions and the open system of courtyard.

Generally, it was recognized that the notions of flexibility here includes some features which can be considered as a guideline to get flexibility for todays architecture of Iran. These attributes are represented in tables 1,3 and 4.

\section{References}

[1] G. Gilani, "Evaluating Flexible Notions In Mass Housing Of North Cyprus Through Learning From Her Rural Vernacular Architecture", Unpublished Master Thesis, Institute Of Graduate Studies And Researc, Eastern Mediterranean University, Famagusta, North Cyprus, (2012).

[2] N. E. Atlas and A. Ozsoy, "Spatial Adaptability And Flexibility As Parameters Of User Satisfaction For Quality Housing", Journal of Building and Environment, vol. 33, no. 5, (1998), pp. 315-323.

[3] V. Eldonk and H. Fassbinder, "Flexible Fixation: the Paradox of Dutch Housing Architecture", Van Gorkum, Assen, Masstricht, (1990)

[4] N. E. Atlas and A. Ozsoy, "Spatial Adaptability And Flexibility As Parameters Of User Satisfaction For Quality Housing", Laurence King Publishing Ltd., (2007), pp. 11.

[5] T. Schneider and J. Till, "Flexible Housing", The Architectural Press, Oxford (2007), pp. 4.

[6] Sh. Li, "A View Of Flexible Housing In China", Unpublished PHD Thesis, Porto Institutional Repository, Italy, (2015).

[7] D. Bernd, "Kongruenz und Divergenz zwischen Nutzanforderungen und dem Flexibilitätsangebot im Wohnungsbau, Fakultät Architektur und Stadtplanung der Universität Stuttgart.", (1982).

[8] D. W. Lans and C. M. Hofland, "Flexibility, how to accommodate unknown future housing requirements", XXXIII IAHS World Congress on Housing Transforming Housing Environments through Design, (2005).

[9] V. Eldonk and H. Fassbinder, "Flexible Fixation: the Paradox of Dutch Housing Architecture", Van Gorkum, Assen, Masstricht, (1990).

[10] R. M. Al-Dakheel, "The Role Of Flexibility In Sustainable Unit Design Arriyadh Commercial Housing Development, ACHD, Case Study (World Congress In Housing Projects Xxxii IAHS).", Trento, Italy (2004).

[11] D. Gülaydın, "A flexibility research on core housing, 132 within the framework of housing design and satisfaction", İstanbul Teknik Üniversitesi, Fen Bilimleri Enstitüsü, Mimarlık Anabilim, (2004).

[12] E. Bakkaloğlu, "A quest on flexibility criteria in the design of residential interior spaces", Unpublished Master thesis, Eastern Mediterranean University, Famagusta, North Cyprus, (2006).

[13] M. Eshraghi and Gh. Bahreni, "review on the role of flexibility in Iranian's traditional housing, case study: h.h. ghafouri's (ghazviniha) building", international journal of science,technology and society, vol 3, (2015), pp. 138-142. 
[14] H. Estaji, "Flexible Spatial Configuration In Traditional Houses, The Case Of Sabzevar", International Journal Of Contemporary Architecture"The New Arch" , vol 1, no. 1 (2014), pp. 26-35.

[15] M.M.Shabani, M.M.Tahir, H.Arjmandi, A.I. Che-Ani, N.A.G. Abdullah, I.M.S.Usman, "Achieving Privacy in the Iranian Contemporary Compact Apartment Through Flexible Design" .

[16] A. Eynifar, "One Pattern For Evaluating Flexibility Of Traditional Iranian House ", Journal Of Beautiful Arts, No. 13 (2004), pp. 6475.

[17] P, Karimi, "Iranian House Discussed By Karim Pirnia ", Abadi Journal,Vol 6, №23, (1996).

[18] P. A. Bell, "Physiological, Comfort, Performance, And Social Effects Of Heat Stress", Journal Of Social Issue, No 37, (1981), pp. 71-94

[19] A. Zand Karimi and B. Hosseini, The Influence Of Iranian Islamic Architecture On Traditional Houses Of Kashan", Second International Conference, Mukogowa Women's Univ, Nishinomiya, Japan (2012). 